\title{
Hope in a depression therapeutic group: a qualitative case study
}

\author{
Esperança num grupo terapêutico de doentes deprimidos: estudo de caso qualitativo \\ Esperanza en un grupo terapéutico de pacientes deprimidos: un estudio de caso cualitativo
}

Ana Isabel Fernandes Querido',11
ORCID: 0000-0002-5021-773X

Carlos António Laranjeira'

ORCID: 0000-0003-1080-9535

Maria dos Anjos Coelho Rodrigues Dixe

ORCID: 0000-0001-9035-8548

'Escola Superior de Saúde, Politécnico de Leiria, Center for Innovative Care and Health Technology (ciTechCare). Leiria, Portugal.

"Center for Health Technology and Services Research. Porto, Portugal.

How to cite this article:

Querido AIF, Laranjeira CA, Dixe MACR. Hope in a Depression Therapeutic Group: A Qualitative Case Study. Rev Bras Enferm. 2021;74(4):e20201309. https://doi.org/10.1590/0034-7167-2020-1309

Corresponding author: Ana Isabel Fernandes Querido E-mail:ana.querido@ipleiria.pt

EDITOR CHEFE: Dulce Barbosa EDITOR ASSOCIADO: Álvaro Sousa

Submission: $08-05-2020$

Approval: 02-04-2021

\section{ABSTRACT}

Objective: to understand the perceptions of hope for people with depression in the context of a therapy group. Methods: using a qualitative case study approach, a semi-structured in-depth interview and a self-report questionnaire were conducted with seven women with depression integrated in a therapy group at a Portuguese day-care psychiatric unit. Data collection and analysis used triangulation of sources. Results: the participants evidenced hope founded on the positive experiences of the past with a strong affiliation component. Hope management is done fundamentally through the interpersonal relationships established between the members of the group, based on communicational patterns that are established on a regular basis, mediated by the group therapist. Conclusion: the therapy group functioned towards the reinforcement of hope in people who experience depression, and it works as a motivation to manage the implications of illness in the participants' life and health project. Descriptors: Case Study; Depression; Hope; Interpersonal Relations; Self-Help Groups.

\section{RESUMO}

Objetivo: Conhecer as percepções de esperança para pessoas com depressão no contexto de um grupo terapêutico. Métodos: Utilizando uma abordagem qualitativa de estudo de caso, foi realizada uma entrevista semiestruturada em profundidade e um questionário de autoavaliação com 7 mulheres com depressão integradas num grupo terapêutico num hospital de dia psiquiátrico português. Na coleta e análise de dados usou-se a triangulação de fontes. Resultados: Os participantes evidenciaram esperança alicerçada nas experiências positivas do passado com forte componente de afiliação. O gerenciamento da esperança é feito fundamentalmente por meio das relações interpessoais estabelecidas entre os membros do grupo, a partir de padrões comunicacionais que se estabelecem regularmente, mediados pelo terapeuta do grupo. Conclusão: O grupo terapêutico funcionou no sentido de reforçar a esperança nas pessoas que vivenciam depressão e funciona como uma motivação para gerir as implicações da doença no projeto de vida e saúde dos participantes.

Descritores: Estudo de Caso; Depressão; Esperança; Relações Interpessoais; Grupos de Autoajuda.

\section{RESUMEN}

Objetivo: Conocer las percepciones de esperanza de las personas con depresión en el contexto de un grupo terapéutico. Métodos: Con un enfoque de estudio de caso cualitativo, se realizó una entrevista en profundidad semiestructurada y un cuestionario de autoinforme con 7 mujeres con depresión integradas en un grupo terapéutico en una unidad psiquiátrica de atención diurna portuguesa. La recopilación y el análisis de datos utilizan la triangulación de fuentes. Resultados: Los participantes evidenciaron esperanza fundada en las experiencias positivas del pasado con un fuerte componente de afiliación. La gestión de la esperanza se realiza fundamentalmente a través de las relaciones interpersonales que se establecen entre los miembros del grupo, basadas en patrones comunicacionales que se establecen de forma regular, mediada por el terapeuta de grupo. Conclusión: El grupo terapéutico funcionó para reforzar la esperanza en personas que experimentan depresión y funciona como una motivación para manejar las implicaciones de la enfermedad en el proyecto de vida y salud de los participantes. Descriptores: Estudio de Caso; Depressión; Esperanza; Relaciones Interpersonales; Grupos de Autoayuda. 


\section{INTRODUCTION}

When thinking about nursing, Florence Nightingale is the place to start; her notes can be found in the book "Nursing, What It Is and What It Is Not". In another of her works- "Sick-Nursing and Health-Nursing" - Nightingale defines health as "not only to be well, but to be able to use well every power we have to use". In this statement, it is apparent that health means more than the mere absence of the disease, a vision that put Nightingale ahead of her time ${ }^{(1)}$. Nursing focuses on human responses to transitions, resulting from events related to health-disease processes and/ or life processes. Meleis (cited in McEwen \& Wills) ${ }^{(1)}$ reinforces that "nurses anticipate, evaluate, diagnose and help clients deal with changes, promoting a maximum level of autonomy, hope and well-being".

The process of promoting hope and well-being is an area of excellence, in which nurses must focus, as it is receptive and sensitive to nursing care and, therefore, an integral content of the core of the subject. Decades of research recognize hope as fundamental to human experience, a critical component of transition processes, and an important predictor of well-being and quality of life ${ }^{(2-3)}$. The relevance of hope for mental health nursing comes from Meininger's thinking and work, where he advocated that health professionals in the field of psychiatry should be sources of hope for patients. In addition, some benefits are associated with promoting hope in people with mental illness, namely faster recovery, early rises and reduced costs associated with treatment ${ }^{(4-5)}$.

Hope as a Nursing focus is defined by the International Classification for Nursing Practice (ICNP)(6) as the "Feelings of having possibilities, trust in others and in future, zest for life, expression of reasons and will to live, inner peace, optimism, associated with setting goals and mobilisation of energy", can constitute a nursing diagnosis (Despair), intervention (Promote hope) or result (Hope).

Hope as an important predictor of mental health, is more relevant than the presence of mental illness, reinforcing the need for intervention in hope in order to guarantee positive results in people's mental health. Despite the recognition of the importance and relevance of hope in mental health, perhaps due to its complexity, the use of hope in clinical practice is still scarce, especially regarding its promotion ${ }^{(4)}$.

Theoretical models about depression often emphasize futureoriented negative cognitions. Beck's cognitive model of depression, for example, considers negative conceptions of the self, the personal world, and the future. The role of hopelessness over the future occupies a crucial part in cognitive narratives of depres$\operatorname{sion}^{(7)}$. Confronted with the potential for motivation to facilitate effective emotional adjustment, Peh et al. ${ }^{(8)}$ propose that hope or hope-based cognitions may be a possible pathway from cognitive re-appraisal to adaptive emotional regulation.

The current evidence refers to the importance of maintaining hope for the future ${ }^{(2)}$, which represents a central position in adhering to treatment and health gains and simultaneously points to the feeling of hopelessness as a predictive factor of long-term mental health difficulties, and consequent failure to achieve treatment goals. Peer support is an evidence-based practice for the treatment of mental illness that lowers the overall cost of mental health services by reducing re-hospitalization rates and days spent in inpatient services, increasing the use of outpatient services. In particular, peer support tends to offer greater levels of self-efficacy, empowerment, and engagement ${ }^{(9)}$. Frequent, proactive contacts that support patients'self-management skills may increase patients' ability to cope with depressive symptoms. Peer-to-peer support enables people to connect with others, share experiences, seek and provide information, advice, and emotional support. The mutual exchange of strategies to cope with the everyday challenges of living with a mental illness is also an important aspect of the peer-to-peer support ${ }^{(10)}$.

\section{Theoretical framework}

Hildegard Peplau is remembered by nurses worldwide as the mother of psychiatric nursing. Peplau made a major contribution to mental health psychiatric nursing through development of the interpersonal relations paradigm that assisted nurses in enlarging their understanding of what transpires during nurse-patient relationships and assisted nurses in helping patients make sense of and learn from their responses to experiences related to health and illness. Taking into account the central assumptions of modern nursing philosophy (Nursing, Person, Health and Environment) (1), Peplau's theory identifies these four concepts.

In the theory of interpersonal relationships, the concept of Nursing translates as a process of interpersonal, therapeutic and educational relationships, through which it develops a cooperative link between nurse and the client. In turn, the concept of Health is characterized by the movement of personality in relation to human processes towards a creative, constructive, and productive life in individual or community plan ${ }^{(1)}$. Concerning the Person concept, Peplau says that man is an interacting organism that lives in an unstable balance. Finally, and with regard to the concept of environment it is characterized by a set of external forces to the person who influences the acquisition of customs and cultural habits through the interpersonal relationships. In this theory, the main key concept is based on the interpersonal process established in the nurse-patient relationship, in which the patient assumes himself as an active component in the therapeutic process ${ }^{(1)}$.

Based on this theoretical framework, we elaborated the following guiding question: How does a therapy group for depression experience hope in a collaborative context?

\section{OBJECTIVE}

The purpose of this study was to understand the perceptions of hope for people with depression in the context of a therapy group.

\section{METHODS}

Qualitative case study research served as the main methodology for this study, following the Consolidated Criteria for Reporting Qualitative research (COREQ) ${ }^{(11)}$.

\section{Ethical aspects}

For the design and development of the study, approval was requested from the Ethics Committee and the Administrative Board of the Hospital Centre where the study was carried out 
(Ref. No.44/2016). In order to preserve anonymity, a pseudonym was assigned to every effective member of the group. Voluntary participation was ensured with informed consent. The participants had the full right to withdraw from the study at any time without consequences.

\section{Study scenario}

This case study was carried out in a Portuguese psychiatric day-care unit with a therapy group led by a psychologist as therapist and a nurse co-therapist [A.Q.]. It is a semi-closed group, in operation for about six years [in relation to the time of data collection - 2016], on a weekly regular basis.

\section{Case study design}

In the design of the qualitative case study, the five components proposed by Yin ${ }^{(12)}$ were incorporated: a) the research questions; b) the propositions; $c$ ) the units of analysis; d) determining the links and relationships between the data; and e) the criteria for interpreting the results.

a) The investigation started with the following questions:

Q1: How does the group perceive hope?

Q2: How do participants manage their hope, and develop capacity for hope management in the context of the therapy group?

b) Starting from the research questions, we enunciated the proposals in order to delimit the investigation so that it is feasible ${ }^{(12)}$. The propositions take the form of statements that will be supported or rejected by the results of the study. Thus, the following propositions were defined: i) the group's therapeutic factors influence hope; and ii) the decision to remain in the group is a promoter of hope.

c) The unit of analysis of the present study is the case itself, that is, the group, with the units of analysis included in the case. The main unit of analysis is the hope of the therapy group, being divided into the subunit: analysis of the individual hope of each member of the group in order to be able to make comparisons ${ }^{(12)}$.

d) The determination of the links between the data is reported in the form of common standards, incorporating several types of analysis using the triangulation of data sources.

e) The interpretation of the results is based on the exploration of the links between the data and the propositions, that is, the correspondence of the various types of information about the case with one or more theoretical propositions.

\section{Study Participants}

Purposeful sampling was used to select the participants. The group is composed by seven women, and the time limit for each member is two years. In this case, the therapy group is based on the assumption of the existence of depression as a pathological nucleus, in which the therapist and the co-therapist are agents who participate in the group, with a low degree of directivity and systematization ${ }^{(13)}$. It was emphasised that the role of the significant other was not as the support person for the client or coach or co-therapist, but rather to give and receive mutual support. This emphasis was to highlight that everyone can benefit from learning new skills and strategies to deal with everyday life, whether they are experiencing depression, to normalise mental illness, foster interdependence rather than dependence, and enhance generalisability of skills ${ }^{(13)}$. The cognitive-restructuring and problem-solving components of the skills training were utilized to increase cognitive and emotional flexibility, thereby allowing the participants to incorporate later skills necessary for agency and pathways thoughts. Based on Peplau's therapeutic relationship model and using the hope model, the principles of successful agency and pathways were gradually introduced to the participants as the group meetings unfolded. Group sessions were held in a reserved physical environment, in which group members participate in creating the therapeutic setting. The group sessions lasted 90 minutes each one. Eight sessions were included in the final analysis.

\section{Data collection methods}

In a case study, it is important to converge sources of data, also known as triangulation, as a means to ensure comprehensive results that reflect the participants' understandings as accurately as possible. Yin ${ }^{(12)}$ concur that triangulation is crucial to performing a case study reliably.

The study was performed from a constructivist point of view, integrating several data sources, namely: semi-structured in-depth interview and a self-report questionnaire. Qualitative interviews were held on separate occasions prior to the quantitative assessments. The participants were invited to provide feedback about the group in an individual semi-structured interview. The interview was guided by the following qualitative open-ended questions: - What were you thinking about when you worked on the group activities? - Did working on the group activities change your hope? Why did you think the group activities did or did not change your hope? Each interview took about 30 to 45 minutes to complete and was transcribed in full. The first author recorded handwritten notes during the collection of interview data, which were later transcribed into a Microsoft Word file. Interviews were anonymised and each participant was given a code number.

Although interviews were the primary method of data collection, we also collected quantitative data, using self-report instruments which were coded using the same code number to each participant. The following instruments were used:

a) Sociodemographic and clinical information (age, gender, marital status, diagnosis, comorbid conditions);

b) Herth Hope Index (HHI) - Scale validated for the Portuguese population by Querido(14) resulting in Herth Hope Index- Portuguese Version (HHI-PT), which demonstrated good internal consistency $(\alpha=0.844)$. It is an instrument used worldwide in several populations, recognized for being especially suitable for use in mental patients in their recovery process. It is a Likert-type ordinal scale composed of ten items, with four response options, scoring from 1 - strongly disagree, to 4 - strongly agree. The scale score ranges from 10 to 40 , with a higher score corresponding to a higher level of hope. HHI-PT is composed of two factors: Factor 1 - Temporality, trust and interconnection is composed of six items $(1,5,6,7,9,10)$ that evaluate the dimensions: temporal, affiliative and contextual of hope; Factor 2 - Positive inner disposition and 
expectations, composed of four items $(2,3,4,8)$ that assess the cognitive, affective and behavioural dimensions of hope;

c) Hope Genogram - Instrument developed by Charepe et al. ${ }^{(15)}$ based on the genogram and ecomap as instruments for assessing the bonds and patterns of family interaction. The hope genogram makes it possible to identify the hope resources of people with chronic illness and the factors that influence hope in groups. Through this instrument it is possible to identify the patterns of interaction in hope, the personal attributes of its members, the spiritual basis, the moralizing memories, allowing a reflection on the family network as strength of resilience and empowerment.

\section{Data analysis and rigour}

For the analysis and treatment of information different types of treatment were applied, depending on the typology of the sources employed. Qualitative data were subjected to content analysis according to Bardin's technique ${ }^{(16)}$. QSR International NVivo software, version 12 was used for initial coding and quantitative content analysis by identifying the most used words and most referenced categories of codes. The interviews were then coded manually using a theoretical approach with the predefined themes as a base. The quantitative data was subjected to computer processing using the SPSS, version 26. Data analysis was carried out by the first author (A.Q.) and C.L. and audited by M.A.D., who took on a supervisory role.

\section{Research team and reflexivity}

This study employed systematic reflexivity by incorporating co-researchers into the analysis, thereby helping to strengthen the analysis processes. In addition to the project leader (psychiatricmental health nurse trained in issues of hope, hopelessness and hope-based interventions within the domain of psychiatry), both co-authors (two senior nurse educators with experience with qualitative and quantitative approaches) also read the entire transcribed material in detail. Finally, the project leader developed a reflexive practice by writing a reflexive diary and by discussing the project frequently with the co-researcher group.

\section{RESULTS}

\section{Sociodemographic and clinical characterization of the participants}

The average age of the participants is 59.14 years (SD $=8.952$ ) ranged between 47 and 74 years. The group's participants are mostly married with difficult and/ or unpleasant relationships, marked by marital conflicts. Family history reveals unstable relationships in all participants, with evidence of unresolved losses and mourning in five of the situations, and marital separations with litigation between spouses. All women have a medical diagnosis of major depression. There is a common history of episodes of profound sadness and suicide attempts. In the clinical records of the participants, complaints of physical symptoms such as headache, insomnia and chronic pain are evident. In three of the situations, there is a record of associated diagnoses of osteoarticular disease and colon dysplasia. Complaints of psychological symptoms focus on irritability, depressed and unstable mood, chronic sadness and emotional lability.

To answer the research questions, two core themes and four overarching categories structured the analysis, as illustrated in Chart 1. These will be described throughout the presentation of results next.

Chart 1 - Core themes and categories

\begin{tabular}{|l|l|}
\hline Core themes & Categories \\
\hline \multirow{2}{*}{ Hope perception } & Personal relationships \\
\cline { 2 - 2 } & Past memories \\
\hline \multirow{2}{*}{ Hope management } & Share personal stories \\
\cline { 2 - 2 } & Awareness about illness \\
\hline
\end{tabular}

\section{Hope perception by the therapy group of people with depression}

Hope as perceived by the therapeutic group of people with depression emerged from the analysis of the responses to HHI-PT (Table 1), triangulated with the content analysis of the group sessions and the hope genogram. The average HHI-PT of the sample was 26.81 (SD = 2.298), ranging from 22.50 to 29 , indicating low to moderate levels of hope.

The highest average indicates people's hope sustained in the ability to interconnect with others $(M=3.29 ; S D=0.488)$. The lowest average corresponded to the presence of a direction in life revealing lower positive inner disposition and expectations, which expressed low hope in the cognitive and behavioural dimension $(M=1.67 ; S D=0.841)$.

Table 1 - Descriptive statistics resulting from the application of Herth Hope Index $(n=7)$

\begin{tabular}{llcccc}
\hline Items & Mean & SD & $\begin{array}{c}\text { Min. } \\
\text { score }\end{array}$ & $\begin{array}{c}\text { Max } \\
\text { Score }\end{array}$ \\
\hline 1 & I have a positive outlook toward life & 2.571 & 0.975 & 1 & 4 \\
2 & I have short and/or long-range goals & 2.429 & 0.534 & 2 & 4 \\
3 & I fell all alone* & 3.143 & 1.069 & 2 & 4 \\
4 & I can see possibilities in the midst of difficulties & 2.500 & 0.763 & 1 & 4 \\
5 & I have a faith that gives me comfort & 3.143 & 0.378 & 3 & 4 \\
6 & I have deep inner strength & 2.857 & 1.069 & 1 & 4 \\
7 & I am able to give and receive caring/love & 3.286 & 0.488 & 3 & 4 \\
8 & I have a sense of direction & 1.667 & 0.471 & 1 & 2 \\
9 & I believe that each day has potential & 2.500 & 0.500 & 2 & 3 \\
10 & I feel my life has value and worth & 2.174 & 0.756 & 2 & 4 \\
Factor 1 & Temporality, trust and interconnectedness & 2.845 & 0.265 & 2.42 & 3.17 \\
Factor 2 & Positive readiness and expectancy & 1.623 & 0.231 & 1.33 & 2 \\
Total & Herth Hope Index-Portuguese version & 2.681 & 0.229 & 2.25 & 2.90 \\
\hline
\end{tabular}

Nota: *Inversed item.

The items with the highest indexes and simultaneously with the highest minimum values are related to the relational and affiliative dimension of hope, namely in item 5, concerning the expression of faith (in the sense of believing in something) ( $M=$ 3.143; $\mathrm{SD}=0.378$; $\operatorname{Min}=3$; $\mathrm{Max}=4$ ) and in the affirmation of the ability to exchange affections in relationships - item $7(M=3.286$; $\mathrm{SD}=0.488$ ). The factor 1 presented a better average, indicating 
that the group participants are more hopeful in terms of time, affiliation and context. It should be noted that these averages ( $M$ $=2.85 ; \mathrm{SD}=0.265)$ are higher than those obtained in the entire instrument $(M=2.68 ; S D=0.229)$.

These results point to a hope based on the positive experiences of the past with a strong affiliation component. The ties established with the direct descendants (children and grandchildren) are decisive for the expression of affection of the participants who consider themselves capable of giving and receiving affection and love (item 7). The positive relationships and strong ties established with the family seem to be a factor of resilience, and function as protectors of mental health, serving as a restraint against suicidal ideation. The relationships expressed in the genograms reveals strong relationships that promote hope with expression of courage, affection and positive energy to face the future. This is highlighted in the reports of the group sessions, expressions such as:

\section{My children are my reason for living. (Joaquina) \\ [...] If it weren't for my granddaughters, I couldn't take this, and I had already put an end... (Maria)}

On the other hand, group participants are found to have marital relationships that threaten hope, also marked by the stigma in the face of mental illness:

[...] what matters to me is to come to the group every week, only if I cannot at all [...]. My husband has already asked me what I am going to do to the crazy group [...], but I do not talk to him as he wants. (Júlia)

The affiliation dimension assessed in this factor highlights the relationships established within the group, in particular those established with the group therapist and colleagues, constituting a reinforcement of personal attributes of hope such as courage, affection and positive energy. From the reports, we highlight expressions such as:

I just think about the doctor... it gives me strength and courage to come, I like it... I feel very good. (Ana)

If I am not here, I have no one to pay attention to me, to be affectionate with me. (Tânia)

From the participants reports during the sessions, negative memories of the past emerged, associated with the experiences of troubled relationships of isolation and deprivation of positive affects during the participants' growth process, which compromise their vision of hope in the present. In this regard, experiences of mistreatment occurred in the midst of relationships with mothers and fathers were shared in groups:

I now take care of my mother, but she was never good for me, she never gave me anything, nor any affection, not even a hug... I wanted to drink in the taverns all day and I didn't want to know about the children. (Maria)

My mother also beat me with a rope. But she was never a good mother; my grandmother was my mother. (Irene)
The expressions and reports of situations of memories that threaten hope seem to happen in the group environment as a favourable context for the expression of feelings and emotions and where hope happens in sharing:

It is not easy to talk about this; I am talking about the group, because the group helped me to endure. (Irene)

I also only managed to say it in the group and it wasn't soon... but now I feel cherished. (Idália)

The answers obtained in item 3, which considers being alone, seem to have been supported by the group experience. During the session, the group participants showed feelings of acceptance and appreciation of the suffering of the other and at the same time the relativization of their own suffering:

Poor thing... this is not done to anyone... (Ana)

The presence of traumatic situations in childhood can have an influence on the participants' ability to perceive the future, have a direction for their life and set short, medium and long-term goals, or even see exit doors from the situation, which reinforces the low rates of hope obtained in factor 2 of HHI-PT.

The difficulty in taking a course in life was sometimes expressed during the group and was often the subject of conversation during moments of informal meeting in the corridor before the therapy session:

my life goes by the taste of others... sometimes I don't even know what I've been doing it..., I might as well end it all! (Ana)

Sometimes I don't even know what I want and much less what I want ... I don't feel like anything anymore and I walk with the wind and be whatever God wants. (Júlia)

In contrast to these assertions, the participants used the context of the therapy group to express dreams and wishes for the future, although in an incipient way and not always shared by everyone. Along with some expressions of self-depreciation, the components of generalized hope and even hope particularized in their behavioural dimension emerge from interactions, showing the ability to express desires, goals and the ability to explore solutions.

It was also observed the power of the group in recognizing the resilience capacities of its participants and in the recognition and appreciation of other attributes of hope of its members, such as the courage to endure adversity and the mobilization of spirituality in the capacity to forgive:

I suffered a lot ..., but I forgave my father. He apologized to me and I forgave him. But my mother never apologized to me. And I kept quiet all my life ... (Idália)

\section{Hope management in the context of the therapy group}

The management of hope is done fundamentally through the relationships established between the members of the group, based on communicational patterns that are established on a regular basis, mediated by the group therapist. With some 
frequency, the establishment of parallel conversations that take place between group members in an interest in mutual knowledge, in addition to the analytical psychotherapeutic approach, arises. From the analysis of the verbatim of the sessions, the group's need to reinforce ties of hope and resilience for its members was emphasized.

One of the episodes that illustrate the sharing of hope in the search for alternative solutions happened following the sharing of Idália about the daughter's pregnancy, accompanied by feelings of revolt in the face of the unexpected of the situation. The group responded with expressions of joy and explored with Idália the positive possibilities of the situation, offering to sew and knit clothes for the baby's layette.

Another episode arose from Antónia's verbalization about the need to acquire clinical material for her husband, quite expensive for her possibilities, but at the same time essential for her husband's life (who needed the material in question to satisfy respiratory needs). In view of this expressed need, Tânia, one of the group's participants started a solidarity movement in order to raise funds for the acquisition of clinical material, breaking the rules of operation of the therapy group.

Despite the bias introduced in the hope psychotherapeutic intervention, these examples attest to the mutuality perceived in the group context that can happen in the continued sharing over time, and the need to give and receive hope through the group. In this regard, it was possible to attest to the group's self-regulation in the search for reinforcement among its members, through the sharing of talents and reinforcement of individual attributes for the construction of their personal and group identity. Participants also demonstrated the need for health information and, above all, information that allows them to better understand the presence of physical and psychological symptoms, in understanding the medical diagnoses they know they have, but who have difficulty managing, especially in related aspects with therapy.

Throughout the sessions, the emerging interaction patterns observed revealed the expression of acceptance of each of the elements in the group, the progressive expression of understanding, and an increase in proactivity in most elements of the group. Júlia often develops positive reinforcement interactivity patterns, demonstrating understanding and empathy for the situation of the other participants. The group accepts her as an opinion leader and develops patterns of interaction in search of its positive reinforcement of hope. This sharing seems to show a reciprocal relationship between people with depression, who within the group and in mutual support find a sense of usefulness.

\section{DISCUSSION}

From the analysis of the expressions and episodes resulting from the group intervention, characteristics of the group emerge in line with those attributed to the mutual aid groups, evidencing in the present case, the need for mediation by a qualified mental health professional. People with depression participating in a therapy group were the object of the case study in order to know the perceptions of hope for people with depression, specifically to characterize their levels of hope; characterize group processes and propose an approach that promotes hope co-participated by the group.
This study suggests that hope-based, goal-focused group psychotherapy is a viable approach to treating specific symptoms and functional outcomes of depression. A group format has the potential to reduce the isolation often present in people who are experiencing depression, while also providing an opportunity for social interaction and emotional support. Encouraging patients to focus on the flexibility, resourcefulness, and wisdom acquired during a lifetime when approaching the goals and challenges faced in the present, coupled with new coping techniques, may have led to the increased levels of hope and the improved social functioning. Indeed, hope theory suggests that such cognitive flexibility is one of the adaptive results of increased pathways thinking ${ }^{(17)}$.

Goldblatt ${ }^{(18)}$ point the psychodynamics of hope in suicidal distress: hope emerges from the attribution of meaning to experience of living with depression, depending on the relational dimension, that is, the presence of another person who offers support. The role of health professionals is also highlighted with regard to strengthening hope and reducing hopelessness and thoughts and suicidal feelings, through counselling and the application of behavioural cognitive techniques. Encouraging participants to express their life stories provide a good opportunity for therapists to highlight hopeful perspectives, especially those which may fade because of other memories or thoughts ${ }^{(19)}$.

The hope indexes obtained confirm the presence of a reasonable hope based on temporality, trust and interconnection and with less positive interior disposition and expectations. Even so, the hope levels obtained by the group are lower than those presented by people with advanced chronic illness in the study by Querido ${ }^{(14)}$, who were in the final stage of life, were able to show greater positive interior disposition and expectations and greater temporality, trust and interconnection than women in the therapy group for depression. These results confirm that people with depression tend to have less hope and less sense of coherence compared to those who do not suffer from the disease and clearly point to the need to bet on hope, if we consider its influence as a factor of resilience and the role of a factor for depression ${ }^{(17-20)}$.

As for the role of the group as a reinforcement of hope in experiencing depression, it was possible to infer that it works as a motivation to manage the implications of depression in the life and health project of the group participants. The positive effect of therapy groups on depression has been given evidence by the literature. We emphasize the study by Breur and Barker ${ }^{(21)}$ who attested to the positive response of participants in the online support groups (people with depression), with improved responses to depression, and self-stigma.

We highlight the psychoeducational needs that emerged from the group's verbatim, which clearly point to a different direction of group conduct than that which was analysed. Alizioti and Lyrakos proposed that psychoeducation is an appropriate intervention to address a wide range of factors that compound adherence to medication and patients' symptoms, such as patients' interpretations of causal models, their sense of hope and control over the illness, and their insight into illness and self-stigma ${ }^{(22)}$

Psychotherapy as an intervention that focuses on the rapid restoration of the individual's psychological balance, in order to obtain maximum symptomatic improvement, promote a positive and supportive person-therapist relationship, reduce discomfort 
subjective and dysfunctional behaviour, promote a greater degree of autonomy of the sick person, taking into account their limitations. By better understanding the problems, the person with depression can develop new human responses to the identified problems, or to others that arise, increasing the feeling of wellbeing $^{(23)}$. The proposed therapeutic approach described here is defined as having emerged from the analysis of the present case study and is based on the therapeutic approach to hope in mutual aid groups, developed by Charepe ${ }^{(15)}$, with contributions from the hope promotion program developed for people with advanced and progressive chronic disease ${ }^{(14)}$. Thus, in view of the results of the analysed group interactions, it is proposed to derive the previous group for a new group, varying the theoretical orientation (centred on the promotion of hope) and the type of functioning, switching to a mutual aid model ${ }^{(15)}$. We consider mutual aid as the relationship established in reciprocity, among people with depression who, in mutual support find a sense of usefulness, operationalized by the sharing of strategies and solutions among their members, allowing a horizontal relationship.

\section{Limitations of the study}

There are a variety of limitations that need to be considered in interpreting the results. The type of group and the psychoanalytic guidance used in conducting it may explain the findings of the study and may have conditioned its results. An additional limitation to the study proved to be the data collection process. Since information obtained during the interview was largely depended on each participant and what was willing to share, the nature of their information was limited to own perspective and lived experiences. Nonetheless, this study's triangulation of data sources helped to verify results, and help to support the accuracy of the themes mined out of the interview transcripts. Another of the study's limitations is the small sample size that only included women. Not intending to extrapolate the results, but in some way its transferability, we still consider it necessary to continue the study of the theme in depth and in extension.

\section{Contributions to the area of nursing and health}

This study points to a great potential and an added value to the mental health nurses' role in improving client outcomes. The dialogues discussed in this case study can potentiate other care practices focused on mutual help in promoting hope. Hope-based psychoeducation could help patients to de-stigmatise the use of medication, while targeting patients'illness-related passivity and fostering improvement of insight into illness. Through the sharing of common experiences associated with the fact of being depressed, the promotion of hope is expected by the integration of personal attributes and resources of hope in the experiences shared with peers. At this point, some strategies could be implemented, namely: a) guidance for the achievement of goals; b) validation of information related to the development of the disease and implications for each one's life project; c) sharing of plans or solutions with a view to empowering the person to deal with their disease; and d) identifying available resources in order to satisfy individual needs. Proposals for diagnostic assessment and individual and group intervention are important contributions to the specialized psychiatric-mental health nursing intervention that can transferred to other contexts, safeguarding the specificities of each.

\section{CONCLUSION}

Peplau highlighted the importance of the interpersonal framework and the nurse-patient relationship to the essence of nursing practice $^{(1)}$. Based on this assumption this case study emphasizes the interpersonal vision of practice as the standard of care across the full range of settings and client groups. Relationships, interactions, and environment are important components of Peplau's theory. This focus was selected to enhance this crucial element of nursing practice, the nurse-patient relationship, and, in particular, to establish interpersonal relations as the cornerstone of psychiatric-mental health nursing practice to assist patients in meeting their needs.

The participants evidenced hope founded on the positive experiences of the past with a strong affiliation component. Hope management is done fundamentally through the interpersonal relationships established between the members of the group, based on communicational patterns that are established on a regular basis, mediated by the group therapist.

The focus on hope allowed the transfer to the context of the clinical practice of different diagnostic instruments, all of which are innovative. This is the case of the hope genogram, which is an extension to the genogram already used by the team in primary health care settings; and the Portuguese version of Herth's Hope Index, validated for the contexts of chronic disease and that was applied for the first time in a therapy group of people with mental illness. We believe that these are valid instruments and that are tools for the construction of evidence-based practice in the autonomous sphere of nursing.

\section{ACKNOWLEDGMENT}

The research team would like to thank the participants who generously shared their time and experience for the purpose of this case study.

\section{REFERENCES}

1. McEwen M, Wills E. Bases teóricas para enfermagem. 4. ${ }^{\mathrm{a}}$ ed. Porto Alegre: Artmed; 2015.608 p.

2. Chan K, Wong FK, Lee PH. A brief hope intervention to increase hope level and improve well-being in rehabilitating cancer patients: a feasibility test. SAGE Open Nurs [Internet]. 2019 [cited 2020 Feb 18];5:1-13. Available from: https://journals.sagepub.com/ doi/10.1177/2377960819844381 
3. Espinoza M, Molinari G, Etchemendy E, Herrero R, Botella C, Baños Rivera R. Understanding dispositional hope in general and clinical populations. Appl Res Qual Life [Internet]. 2016 [cited 2020 Feb 18];12(2):439-50. Available from: https://link.springer.com/article/10.1007/ s11482-016-9469-4

4. Frost BG, Tirupati S, Johnston S, Turrell M, Lewin T, Sly K, et al. An Integrated Recovery-oriented Model (IRM) for mental health services: evolution and challenges. BMC Psychiatr. 2017;17:22. https://doi.org/10.1186/s12888-016-1164-3

5. Querido Al. A esperança como foco de enfermagem de saúde mental. Rev Port Enferm Saúde Mental. 2018;(spe6):06-08. https://doi. org/10.19131/rpesm.0206

6. International Council of Nurses (ICN). ICNP@ Browser [Internet]. 2019 [cited 2020 Apr 20]. Available from: https://www.icn.ch/what-we-do/ projects/ehealth/icnp-browser

7. Thimm JC, Holte A, Brennen TW, Catharina EA. Hope and expectancies for future events in depression. Front Psychol [Internet]. 2013 [cited 2020 Apr 20];4:470. Available from: https://www.frontiersin.org/articles/10.3389/fpsyg.2013.00470/full

8. Peh CX, Liu J, Bishop GD, Chan HY, Chua SM, Kua EH, et al. Emotion regulation and emotional distress: the mediating role of hope on reappraisal and anxiety/depression in newly diagnosed cancer patients. Psycho Oncol [Internet]. 2017 [cited 2020 Mar 19];26(8):1191-7. Available from: https://pubmed.ncbi.nlm.nih.gov/27723939/

9. Farkas M, Boevink W. Peer delivered services in mental health care in 2018: infancy or adolescence? World Psychiatry [Internet]. 2018 [cited 2020 Mar 19];17(2):222-4. Available from: https://www.ncbi.nlm.nih.gov/pmc/articles/PMC5980530/

10. Naslund JA, Aschbrenner KA, Marsch LA, Bartels SJ. The future of mental health care: peer-to-peer support and social media. Epidemiol Psychiatr Sci [Internet]. 2016 [cited 2020 Apr 12];25(2):113-22. Available from: https://pubmed.ncbi.nlm.nih.gov/26744309/

11. Tong A, Sainsbury P, Craig J. Consolidated criteria for reporting qualitative research (COREQ): a 32-item checklist for interviews and focus groups, Int J Qual Health Care. 2007;19(6):349-57. https://doi.org/10.1093/intqhc/mzm042

12. Yin RK. Case Study Research. Design and Methods. 6th Edition. Thousand Oaks: Sage Publications; 2018. 352p.

13. Fortinash K, Worret P. Psychiatric mental health nursing. 5th ed. St. Louis: Elsevier; 2014. 687p.

14. Querido Al. A promoção da Esperança em fim de vida: teste da efetividade de um programa de intervenção em pessoas com doença crónica avançada e progressiva [Internet] [Tese]. Lisboa: UCP; 2013 [cited 2020 Apr 20]. Available from: https://iconline.ipleiria.pt/ handle/10400.8/4050

15. Charepe Z. O impacto dos grupos de ajuda mútua no desenvolvimento da esperança dos pais de crianças com doença crónica [Internet] [Tese]. Lisboa: UCP; 2011 [cited 2020 Apr 20]. Available from: https://repositorio.ucp.pt/handle/10400.14/7328

16. Bardin, L. Análise de conteúdo. Lisboa: Edições 70; 2016. 225p.

17. Leite $A$, Medeiros AGAP, Rolim C, Pinheiro KSCB, Beilfuss M, Leão M, et al. Hope theory and its relation to depression: a systematic review. Ann Psychiatr Clin Neurosci [Internet]. 2019 [cited 2020 Oct 3];2(2):1014. Available from: http://www.remedypublications.com/open-access/ hope-theory-and-its-relation-to-depression-a-systematic-review-168.pdf

18. Goldblatt M. The psychodynamics of hope in suicidal despair: the Scandinavian Psychoanalytic review [Internet]. 2017 [cited 2020 Oct 3];40(1):54-62. Available from: https://www.tandfonline.com/doi/abs/10.1080/01062301.2017.1312219?journalCode=rspr20

19. Kivlighan DM, Paquin JD, Hsu Y-KK, Wang L-F. The mutual influence of therapy group members' hope and depressive symptoms. Small Group Res [Internet]. 2016 [cited 2020 Oct 3];47(1):58-76. Available from: https://journals.sagepub.com/doi/abs/10.1177/104649641560563 8?journalCode=sgrd

20. Ritschel LA, Sheppard CS. Hope and depression. In Gallagher M, Lopez S (Eds.). Oxford library of psychology: the Oxford handbook of hope. Oxford University Press; 2018. p. 209-219

21. Worrall H, Schweizer R, Marks E, Yuan L, Lloyd C, Ramjan R. The effectiveness of support groups: a literature review. Mental Health Soc Incl [Internet]. 2018 [cited 2020 Apr 14];22(2):85-93. Available from: https://www.emerald.com/insight/content/doi/10.1108/ MHSI-12-2017-0055/full/html

22. Alizioti A, Lyrakos G. Measuring the effectiveness of psychoeducation on adherence, depression, anxiety and stress among patients with diagnosis of schizophrenia. a control trial. Curr Psychol [Internet]. 2019[cited 2020 Apr 19]. Available from: https://link.springer.com/ article/10.1007/s12144-019-00255-4

23. Ordem dos Enfermeiros (OE). Regulamento dos Padrões de Qualidade dos Cuidados Especializados em Enfermagem de Saúde Mental [Internet]. Lisboa: Ordem dos Enfermeiros; 2015 [cited 2020 Apr 19]. Available from: https://www.ordemenfermeiros.pt/arquivo/legislacao/ Documents/LegislacaoOE/Regulamento_356_2015_PadroesQualidadeCuidadosEspEnfSaudeMental.pdf 